\title{
Assessing the wall-to-wall spatial and qualitative dynamics of the brazilian pasturelands, between 2010 and 2018, based on the analysis of the Landsat Data Archive
}

Claudinei Oliveira dos Santos ${ }^{1 *}$, Vinícius Vieira Mesquita ${ }^{1}$, Leandro Leal Parente ${ }^{1}$, Alexandre de Siqueira Pinto ${ }^{2}$, Laerte Guimaraes Ferreira Jr. ${ }^{1}$

${ }^{1}$ Image Processing and GIS Laboratory (LAPIG), Federal University of Goiás (UFG), Goiânia GO 74001-970, Brazil; claudineisantos@discente.ufg.br | claudineisan@pastoepixel.com, vieiramesquita@gmail.com, leandro.parente@,opengeohub.org, 1aerte@ufg.br

${ }^{2}$ Ecology Department, Federal University of Sergipe, Brazil6; xansiqueira@academico.ufs.br

* Correspondence: claudineisantos@discente.ufg.br; claudineisan@pastoepixel.com

\begin{abstract}
The Brazilian livestock is predominantly extensive, with approximately $90 \%$ of the production being sustained on pasture, which occupies around $20 \%$ of the territory. In the current climate change scenario and where cropland is becoming a limited resource, there is a growing need for a more efficient land use and occupation. It is estimated that more than half of the Brazilian pastures have some level of degradation; however there is still no mapping of the quality of pastures on a national scale. In this study, we mapped and evaluated the spatio-temporal dynamics of pasture quality in Brazil, between 2010 and 2018, considering three classes of degradation: Absent (D0), Intermediate (D1), and Severe (D2). There was no variation in the total area occupied by pastures in the evaluated period, in spite of the accentuated spatial dynamics, with a retraction in the center-south and expansion to the north, over areas of native vegetation. The percentage of non-degraded pastures increased $\sim 12 \%$, due to the recovery of degraded areas and the emergence of new pasture areas as a result of the prevailing spatial dynamics. However, about 44 Mha of the pasture area is currently severely degraded. The dynamics in pasture quality were not homogeneous in property size classes. We observed that in the approximately 2.68 million properties with livestock activity, the proportion with quality gains was twice as low in small properties compared to large ones, and the proportion with losses was three times greater, showing an increase in inequality between properties with more and less resources (large and small, respectively). The areas occupied by pastures in Brazil present an unique opportunity to increase livestock production and make available areas for agriculture, without the need for new deforestation in the coming decades.
\end{abstract}


Keywords: landsat; pasture degradation; brazilian pasturelands dynamics; low carbon agriculture

\section{Introduction}

Brazil has the second largest cattle herd in the world, being the second largest producer and the largest exporter of meat (ABIEC, 2020; IBGE, 2020; USDA, 2020). However, its livestock is not very productive, requiring a herd larger than the European Union and the United States combined, to produce approximately half of the beef achieved by both (ABIEC, 2020; USDA, 2020). One of the reasons for its low productivity is that the Brazilian livestock is predominantly extensive, with more than $90 \%$ of the herd being sustained on pasture (Dias Filho, 2011a). For this reason, pastures occupy a large territorial extension, approximately $20 \%$ of the country's territory (Parente et al., 2019). In recent decades, there has been a marked growth in the livestock activity and, consequently, a great expansion in areas occupied by pastures (Vieira-Filho and Fishlow, 2017). The expansion of the area occupied by pastures and deforestation are strongly correlated, since forage cultivation is usually the first use in areas of conversion of native vegetation (Barona et al., 2010; Cardille and Foley, 2003; Parente et al., 2019). Likewise, the process of loss of productivity at levels that make the rancher abandon their land and look for places to install new pastures needs to be understood so that more efficient management practices can be introduced.

Pasture degradation is one of the main causes of productivity loss in the Brazilian livestock system, and a challenge faced by the sector for decades (Oliveira et al., 2004; Volpe et al., 2008). The process of degradation of pastures can take place over several years and is characterized by loss of productivity, decrease in the supply of food for the livestock and, consequently, reduction in the carrying capacity (Dias Filho, 2014). There are several factors that can lead to the degradation process of pastures, most of which are linked to inadequate management practices, including the choice of forage, cattle stocking and fertilization, among others (Dias Filho, 2011a; Lahsen et al., 2016). On the other hand, proper management can recover areas with low productivity and increase livestock production, thus contributing to a reduction in deforestation and, consequently, in GHG emissions (Greenhouse Gases) related to the sector (Braz et al., 2013; Bustamante et al., 2012; FAO, 2019; L. F. Pereira et al., 2018; West et al., 2014). 
In this context, initiatives have emerged that encourage the recovery of degraded pastures and the adoption of management strategies that promote gains in productivity and sustainability, and reduce environmental impacts (Alves-Pinto et al., 2015; EMBRAPA, 2021; ICV, 2021). A highlight in this regard is the ABC Plan (Low Carbon Agriculture Plan, implemented by the Ministry of Agriculture, Livestock and Food Supply), a federal government initiative approved in 2011, which was developed in order to achieve the international commitments assumed by Brazil related to the reduction of GHG emissions (MAPA, 2012). As part of this plan, the Degraded Pasture Recovery (RPD) program was created, with the goal of promoting the recovery of 15 Mha of degraded pastures across the country by the year 2020, which represents more than $8 \%$ of the Brazilian pastures (Latawiec et al., 2014; MAPA, 2012). Therefore, the mapping and analysis of pasture quality at a national scale is essential both to assess the effectiveness of initiatives such as the ABC Plan, as to support future actions that seek to promote a more efficient use of areas occupied by pastures in Brazil.

Orbital remote sensing has been of fundamental importance in initiatives for mapping pastures, since the increase in image availability, combined with the advancement of analysis techniques and computational capacity, has enabled a better assessment of changes in land use and coverage at an unprecedented spatio-temporal scale (Souza et al., 2020). In addition to monitoring the dynamics of the areas covered by pastures, it is also possible to use remote sensing for qualitative assessments. In this context, studies aimed at mapping and monitoring the quality of pastures through remote sensing have been conducted in various regions of the world (Gao et al., 2006; Olexa and Lawrence, 2014; Reinermann et al., 2020). Most of these studies used moderate spatial resolution data (MODIS) (Aguiar et al., 2017; Arantes et al., 2018; O. J. R. Pereira et al., 2018). More recently, high spatial resolution data have been used in pasture quality assessments and biomass estimates (Brito et al., 2018; Chen et al., 2021; Dos Reis et al., 2020). Among the products most used for these qualitative analyzes is the NDVI (Normalized Difference Vegetation Index), considered a "proxy" of vegetative vigor and forage productivity (Arantes et al., 2016). In Brazil, several initiatives aiming to assess the quality of pastures using satellite data have been conducted at regional scales (Andrade et al., 2013), or covering biomes (O. J. R. Pereira et al., 2018), and in some cases for the entire national territory (Aguiar et al., 2017; Arantes et al., 2018). However, there is still no mapping of the quality of the Brazilian pastures at high spatial resolution (e.g. Landsat-based) and that enables the understanding of the dynamic patterns of this land use at the national scale. 
The identification of degraded pastures in Brazil is essential to support public policies related to their recovery, and given the dimensions of the Brazilian livestock, is of global importance. In this context, in this study the objectives were: (a) to present an analytical approach for mapping and monitoring the quality of pastures in Brazil; (b) characterize the dynamics and spatial pattern of the state of degradation of the Brazilian pastures in the period between 2010 and 2018; (c) evaluate the relationship between resources received by rural properties (private agricultural land of any size) under the ABC Plan and the increase in the quality of pastures.

\section{Data and methods}

\subsection{Pasture quality classification}

The classification of land cover in pasture was obtained from a study that mapped and analyzed the dynamics of pasture areas in Brazil from 1985 to 2017 (Parente et al., 2019). In the classification, the authors used the entire collection of satellite data corresponding to the mapped period, and used the Random Forest classifier, a machine learning algorithm. The maps of this time series were extended by the authors until the year 2019 and made available via the Digital Atlas of the Brazilian Pastures platform (LAPIG, 2020). For the analyzes in this study, we used the pasture classification maps related to the years 2010 and 2018.

The quality of the Brazilian pastures was estimated based on the classification initially proposed to investigate degraded pastures in Tibet (Gao et al., 2006). Subsequently, adjustments were made to this method in three studies in Brazil that evaluated: a) the state of degradation of pastures in three watersheds in the state of São Paulo (Andrade et al., 2013); b) the characterization of the annual dynamics of pastures in a watershed in Minas Gerais (L. F. Pereira et al., 2018); and c) the dynamics of pasture quality in rural settlements in Goiás (Gosch et al., 2020).

The classification of the quality of pastures throughout the Brazilian territory used in this work consisted of three sequential steps: (1) Pre-processing of data indicating the state of degradation of pastures, so that they were comparable between the years analyzed. At this stage the noisy data were removed, the availability of data equalized, the spectral difference between the sensors corrected and the data normalized by homogeneous regions; (2) Stratification of the images of each year analyzed, into Pasture Degradation Classes. At this stage the pasture area in each degradation class was identified; later, the classified maps were compared to analyze 
the dynamics of the classes between the years considered; (3) Calculation of the Pasture Degradation Index by Property (IDP) from pasture area by degradation class.

\subsection{Pre-processing}

The classification of pasture status was based on NDVI values - Normalized Difference Vegetation Index from Landsat satellites (Rouse et al., 1973). The NDVI, which varies between -1 and 1 , is positively correlated with vegetation vigor (equation 1 ). Therefore, it has been used to assess the state of degradation and for biomass estimates of pastures (Eckert et al., 2015; Gargiulo et al., 2020; O. J. R. Pereira et al., 2018). At the beginning and end of the period analyzed (i.e. 2010 and 2018), data from the Landsat 5 and Landsat 8 satellites, respectively, were used. Landsat 5, equipped with the Thematic Mapper (TM) sensor, was launched in 1984 and was in operation until early 2013, and Landsat 8, equipped with the Operational Land Imager (OLI) sensor and launched in 2013, is currently in operation. Launched into space with a difference of 29 years, the satellites show significant differences, with Landsat 8 presenting greater image availability and finer spectral resolution.

Equation 1

$$
N D V I=\frac{N I R-R E D}{N I R+R E D}
$$

Where NDVI is the normalized difference vegetation index; NIR is the reflectance of electromagnetic radiation in the near infrared spectrum, and RED is the reflectance of electromagnetic radiation in the red light spectrum.

To classify pasture areas at the beginning and end of the analyzed period, we used median NDVI images. In the median calculation, all images available in a 24-month time window were used - necessary to contemplate a complete climatic year - comprising the second semester of the previous year, the year of interest and the first semester of the subsequent year (i.e. July 2009 to June 2011 and July 2017 to June 2019). In order for the median images to be equivalent and comparable in spatial and temporal dimensions, the differences in image availability and spectral resolution between the two satellites were spectrally corrected (i.e. Landsat 5 and Landsat 8), the areas covered by clouds, shadows and noise were removed, and only scenes with less than $80 \%$ of cloud and shadow coverage were used. 


\subsection{Pasture degradation classes}

The median NDVI images were normalized by biomes in order to reduce the expected differences in the values of this parameter in response to edaphoclimatic conditions, making the index equivalent between different biomes (equation 2):

Equation 2

$$
\text { NDVInorm }=\frac{\text { NDVI }- \text { NDVImin }}{\text { NDVImax }- \text { NDVImin }}
$$

Where NDVInorm is the normalized NDVI, ranging from 0 to 1 ; NDVI is the Normalized Difference Vegetation Index; NDVImin is the average of $1 \%$ of the lowest values of all NDVI data in the unit of analysis (i.e. biome) and the NDVImax is the average of $1 \%$ of the highest values in this same unit of analysis, considering the combined periods (i.e. July 2009 to June 2011 and July 2017 to June 2019).

The resulting NDVInorm images were stratified into pasture degradation state classes. Andrade et al. (2013) evaluated four classes of pasture degradation status: (Absent [>0.6], Mild $[>0.5$ and $<0.6]$, Moderate $[>0.4$ and $<0,5]$ and Severe $[<0.4])$, and concluded that the method is effective in identifying the Absent and Severe classes, however it does not distinguish the Mild and Moderate classes from each other. Therefore, we grouped the Mild and Moderate classes in order to work with only the three degradation state classes in which the method was effective in distinguishing (Absent [>0.6], Intermediate $[>0.4$ and $<0.6]$ and Severe $[<0.4]$ ) (figure 1). Degradation classes, henceforth, are referred to by the abbreviations D0 (Absent), D1 (Intermediate), D3 (Severe), and areas not mapped in a given year are referred to by NP (Not Pasture).

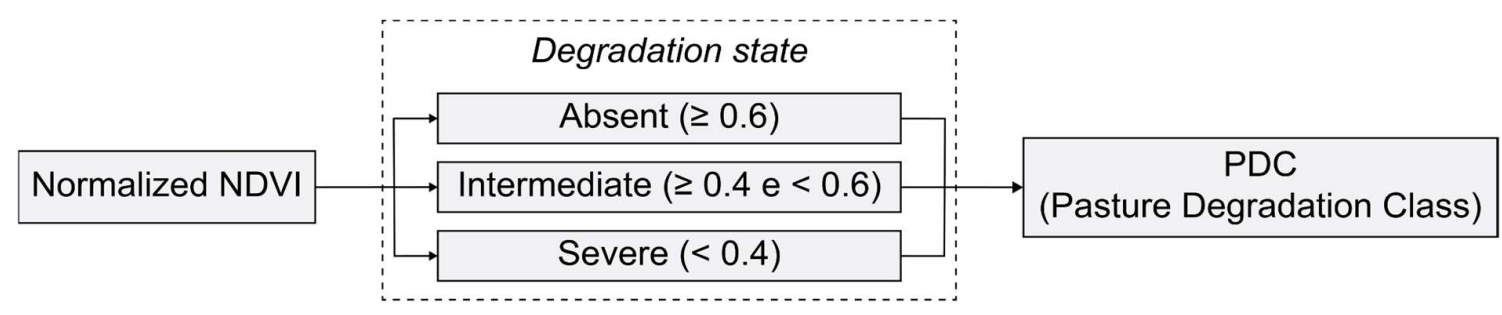

Figure 1. Flowchart depicting the stratification of the NDVInorm (normalized NDVI) into three classes of degradation state (i.e. Absent, Intermediate and Severe). 


\subsection{Pasture Degradation Index by Property (IDP)}

The Pasture Degradation Index by Property (IDP) was used to assess the dynamics of pasture quality in the Brazilian rural properties. More specifically, the gain, loss or stability were assessed in terms of the state of degradation of small, medium and large rural properties. Likewise, the IDP was also calculated in areas under contract of the ABC Plan for the recovery of degraded pastures (RPD), in the period between 2016 and 2017. It is expected that in these polygons (i.e. areas of interest) the quality of pastures will have increased, and with that the IDP has reduced.

The IDP was calculated for each rural property with a minimum pasture area of one hectare and occupying more than $10 \%$ of the property. This criterion was used to analyze only properties with effective use in the livestock activity. The property boundaries were obtained from the CAR (Rural Environmental Registry) database of the Brazilian forestry service which in the period of analysis consisted of 5.5 million rural properties. To calculate the IDP, we considered the four classes of degradation state proposed by Andrade et al., (2013). The IDP varies between 1.0 and 4.0 and was calculated according to equation 3 (Andrade et al., 2013):

Equation 3

$$
I D P=\frac{\left(\sum_{i=1}^{n} \quad p i * A i\right)}{A}
$$

Where IDP is the Pasture Degradation Index; Pi the weight assigned to the degradation state class $\mathrm{i}$; Ai the pasture area in the degradation state class $\mathrm{i}$; and $\mathrm{A}$ is the total pasture area in the unit of analysis.

Following the provisions of the legislation governing the agrarian reform in Brazil (Law No. 8,629), we distributed the rural properties into three size groups according to the number of fiscal modules: Small, up to four; Averages, between four and fifteen; Large, over 15 fiscal modules. The differences in the IDP values of each property by group, between 2010 and 2018, were distributed into three classes, in order to assess the dynamics of pasture quality over time in three categories: Stable, PDI differences between 0.0 and 0.5 ; Increased, differences greater than -0.5 ; Reduced, differences less than +0.5 .

\subsection{Evaluation of pasture recovery efficiency through ABC Plan resources}

To assess the efficiency of the RPD program in Brazil, 1,693 polygons that had contracts with the Central Bank under the ABC plan were analyzed. These contracts were established 
during 2016 and 2017 and covered all Brazilian regions, with the highest percentage of contracts in the Midwest (36.6\%), followed by the North (26.1\%), and the Southeast, Northeast and South regions, with respectively $24.6 \%, 8.6 \%$ and $4.1 \%$ of total contracts. With the exception of the Northeast, the percentage of contracts per region was proportional to the area of pastures, that is, regions with a greater proportion of pastures had a greater proportion of contracts.

The IDP values of each polygon were compared between 2010 and 2018, in order to identify whether there was improvement, deterioration or stability in the condition of the pastures. For this, we grouped the polygons according to the same criteria used to evaluate rural properties and we considered that the use of resources was effective when quality gains were detected.

\subsection{Accuracy analysis}

An accuracy analysis of the pasture degradation classes was conducted to assess the quality of the results. The analysis was restricted to the Cerrado biome, due to limitations of collecting information in all the Brazilian biomes. The prioritization of this biome is strategic, as it concentrates one third of the Brazilian pastures $(\sim 32.8 \%)$ and one third of the cattle herd $(\sim 34.0 \%)$. In an experiment conducted in the biome between $04 / 2019$ and $01 / 2020$, we evaluated the condition of pastures at 53 points, in four moments according to climatic seasonality (January - Peak rain, April - Rain-dry transition, July - Peak of drought, October Transition dry to rain). At each point, based on the evaluation of seven parameters indicating the condition of the pasture (Height, Density, Soil Cover, Homogeneity, Availability of Green Leaf, Leaf/Stem Ratio, Age of tillers), we classified the pasture according to degradation classes Absent, Intermediate or Severe. From these points, we generated a confusion matrix and calculated the overall accuracy of each pasture condition class (Olofsson et al., 2014).

For a detailed description of the data and analysis strategies considered in this work, access the supplementary material.

\section{Results}

\subsection{Spatiotemporal dynamics of pasture quality in Brazil}

The estimate of areas covered by pasture in 2010 and 2018 resulted in similar values, totaling 171.6 Mha and 170.7 Mha, respectively; i.e. there was a reduction of 0.9 Mha in the 
area classified as pasture in the period considered in this study (figure 2). On the other hand, a surface equivalent to 31.7 Mha was no longer classified as pasture in 2018 , that is, it was converted to other uses or covers, while $\sim 30.8$ Mha was incorporated into this land use class in that same year.

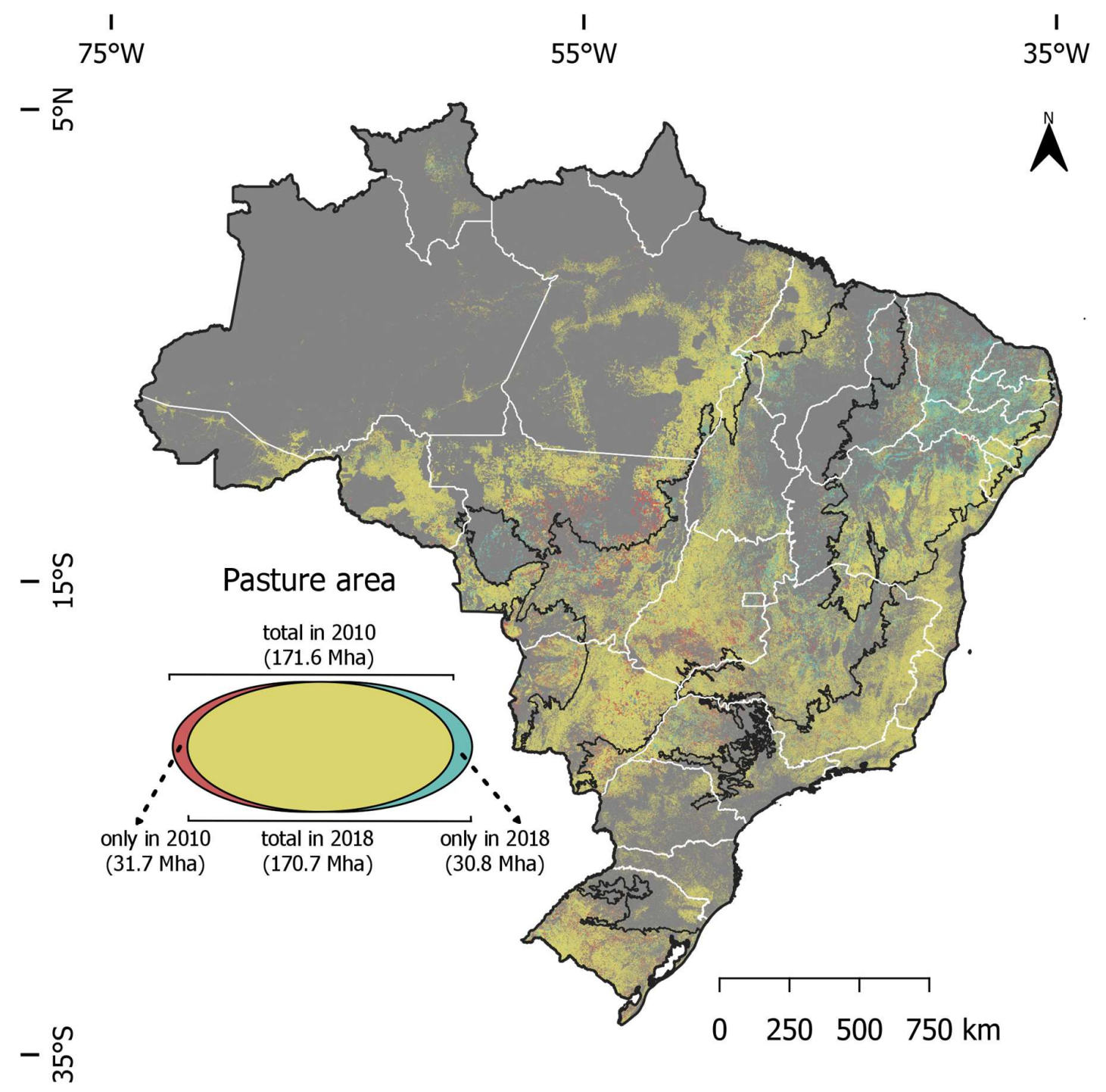

Figure 2. Areas occupied by pastures in Brazil in 2010 and 2018 (https://pastagem.org/atlas). [31.7 Mha (million hectares) mapped only in 2010; 139.9 Mha mapped in 2010 and 2018; 30.8 Mha mapped only in 2018]

The breakdown of pasture areas into classes allowed us to realize that, despite the small variation in total pasture coverage between 2010 and 2018, there was a substantial change between the degradation state classes. In 2010, the area classified as Absent degradation (D0) corresponded to $29.1 \%$ of pastures, while $38.8 \%$ was classified as Intermediate (D1) and $32.1 \%$ as Severe (D2) (figure 3). However, the proportions of D0, D1 and D2 at the end of the period 
evaluated were, respectively, $41.1 \%, 32.2 \%$ and $26.7 \%$. That is, we observed an increase in the area occupied by pastures with better quality, as there was an increase in 2018 in D0 (from 48.8 to $68.3 \mathrm{Mha}$ ), and a reduction in D1 (from 65.0 to $53.4 \mathrm{Mha}$ ) and in D2 (from 53.9 to 44.3 Mha).

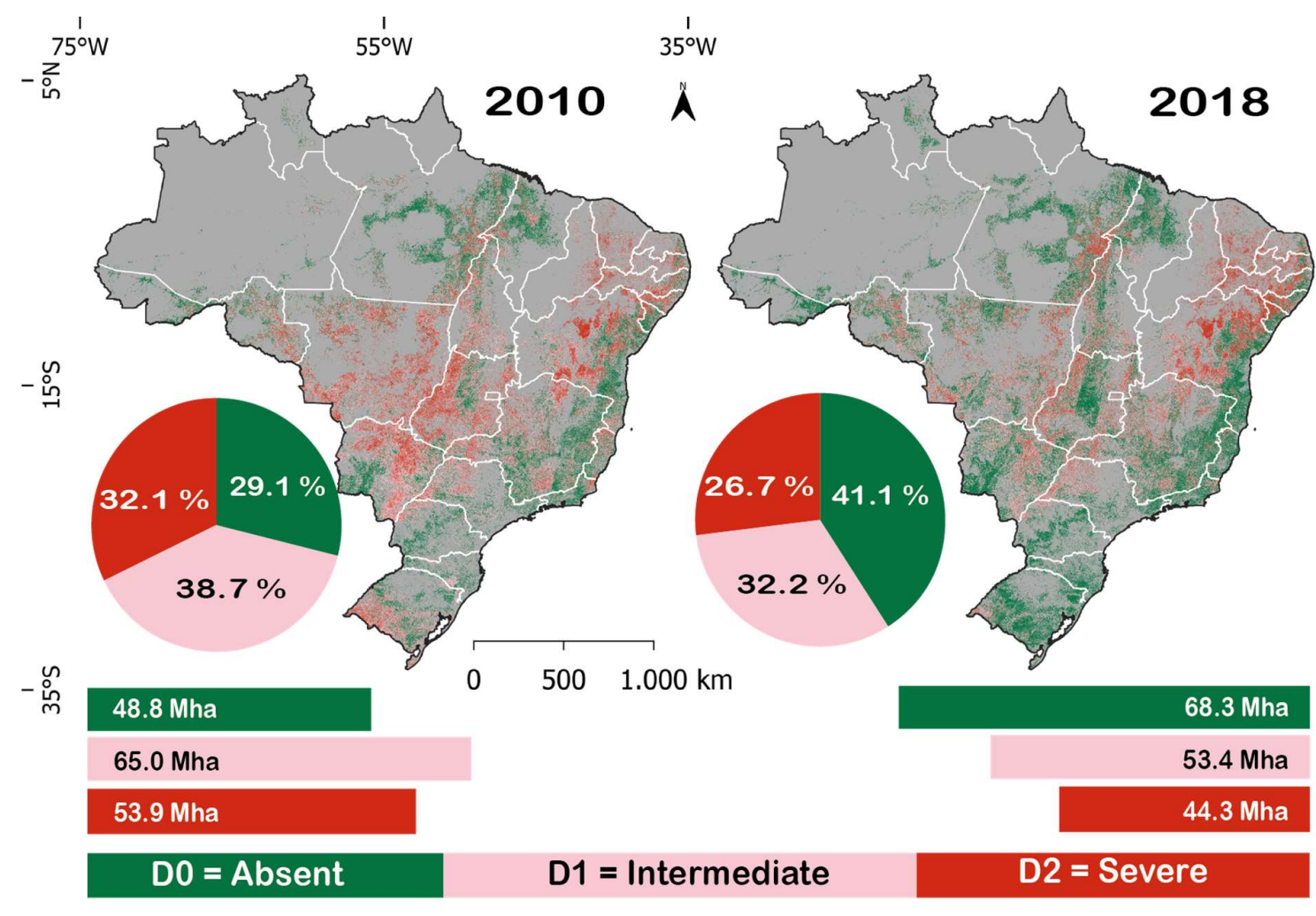

Figure 3. Pasture area in Brazil, according to three classes of degradation state (D0: Absent, D1: Intermediate and D2: Severe), for the years 2010 and 2018.

The smallest error of omission was observed for the severe degradation class $(78 \%$ of producer accuracy), followed by the absent class (65\% of producer accuracy), with an overall accuracy of $58 \%$ (table 1). A clear distinction between these two classes (D0 and D2) is essential, as they include the areas that need to be kept productive and the areas that need to be restored. The intermediate class had a lower accuracy (69\% user accuracy and 46\% producer accuracy), as it is a more dynamic class, and, apparently, a temporary condition of the pasture. Pastures in this class will advance to severe degradation (e.g. in areas of speculation or land grabbing, and abandoned areas) or return to the non-degraded class (e.g. in areas with traditional 
management, where pasture is used until the loss of productivity, being then reformed, in a recurring process).

Table 1. Accuracy analysis of pasture quality mapping in 2018, based on 53 points evaluated in the field, in the Cerrado biome. PA* = Producer Accuracy; UA* = User Accuracy;

\begin{tabular}{ccccc}
\hline & Absent & Intermediate & Severe & UA* \\
\hline Absent & 13 & 8 & 1 & $59 \%$ \\
Intermediate & 4 & 11 & 1 & $69 \%$ \\
Severe & 3 & 5 & 7 & $47 \%$ \\
\hline PA* $^{*}$ & $65 \%$ & $46 \%$ & $78 \%$ & \\
\hline
\end{tabular}

The temporal dynamics of each degradation class contributed to verifying precisely the changes between pasture quality states over time (figure 4). Almost half of the area classified as D0 in 2010 (42.9\%) changed its degradation class in 2018 . We observed that $15.8 \%$ went to D1 and $4.9 \%$ went to D2, indicating a loss of quality in both cases. Another $22.3 \%$ were classified as NP. On the other hand, the increase in area and percentage observed in the D0 class in 2018 was due to the improvement in quality in areas coming from D1 (31.9\%) and D2 (7.3\%), but also due to the change in land use, as $19.9 \%$ came from NP.

A marked dynamic was observed in D1, as $58.1 \%$ of the area of this class in 2018 came from changes in other classes, mainly with the gain in quality in class D2 pastures $(28.5 \%)$, followed by newly converted areas (15.2\%). The areas that had a loss of quality (from D0) contributed $14.4 \%$. Approximately $54.5 \%$ of the area classified as D2 in 2018 already belonged to this class in 2010, that is, there was the maintenance of a considerable area of pasture in a state of severe degradation (24.1 Mha) over time. About 9.6 Mha in this class were areas that lost quality, and 8.2 Mha were areas not mapped in 2018. The areas that were no longer mapped as pastures in the evaluated period were predominantly areas classified as low-productive in 2010, mainly class D1 (35.3\%), followed by class D2 (30.3\%). Non-degraded areas that were no longer mapped as pastures totaled $34.4 \%$ (D0). 


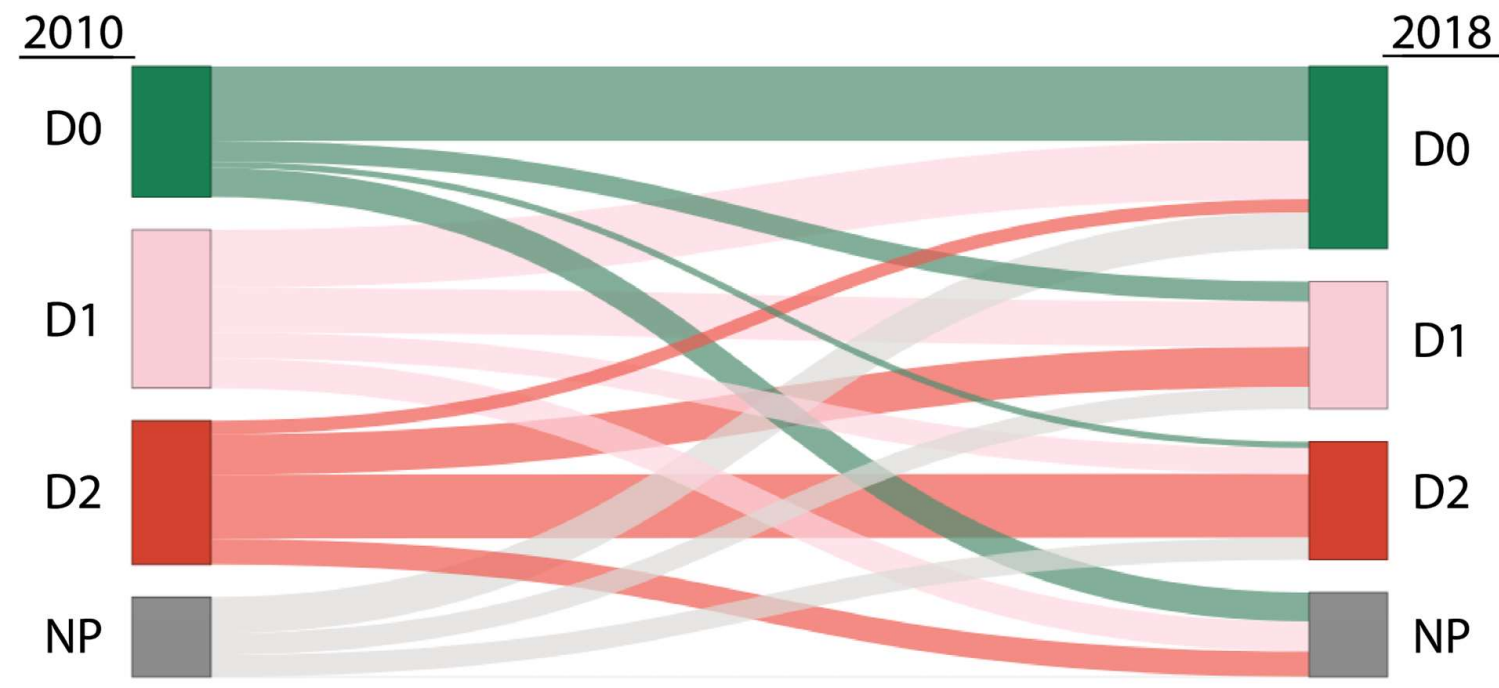

Figure 4. Dynamics of pasture degradation in Brazil between 2010 and 2018. Degradation classes: D0 = Absent, D1 = Intermediate and D2 $=$ Severe. $\mathrm{NP}=$ area not mapped as pasture.

\section{2. $\quad$ Factors related to variation in pasture quality by rural property}

Pasture represents an important land use in Brazil, since almost half (49.1\%) of the approximately 5.5 million properties available in the CAR base have livestock among their economic activities, considering the inclusion criteria for analysis of the IDP. The vast majority of the rural properties in Brazil are comprised of Small units (91.4\%), followed by Medium (6.4\%) and Large (2.2\%) (figure 5). When evaluating the evolution of the quality of pastures by rural property between 2010 and 2018, regardless of the size of the property, it was possible to observe that about $60 \%$ were classified as Stable (table 2). In this same period, there was an increase in quality in a quarter of the properties (25.3\%) and a reduction in $15.8 \%$ (table 2). We noticed that the quality dynamics of pastures was affected by the size of the property, as small units presented a reduction in quality twice as high as compared to medium-sized ones, and almost three times greater than in large ones $(16.6 \%, 8.9 \%$ and $6.2 \%$, respectively) (table 2 ). Considering the gain in quality over time, the Large properties showed an increase about twice as much as the Small ones (41.2\% and $24.3 \%$, respectively).

Changes in the quality of pastures on properties are not evenly distributed in the country, with a predominance of increase in quality in the South and Center-West regions (figure 6). The class of medium properties showed the least evidence of heterogeneity in spatial distribution (figure 6B), with the three levels of pasture condition being observed in the 
different regions. On the other hand, the class of small properties presented a predominance of loss in pasture quality in the states of Maranhão, Minas Gerais, Bahia, and in the limits between the states of Tocantins and Pará (figure 6A). And in large properties, which are predominant in regions with agricultural frontiers and regions with a more recent history of land use, there was an increase in the quality of pastures, especially in the states of the Center-West region (Goiás, Mato Grosso and Mato Grosso do Sul) ( figure 6 C).

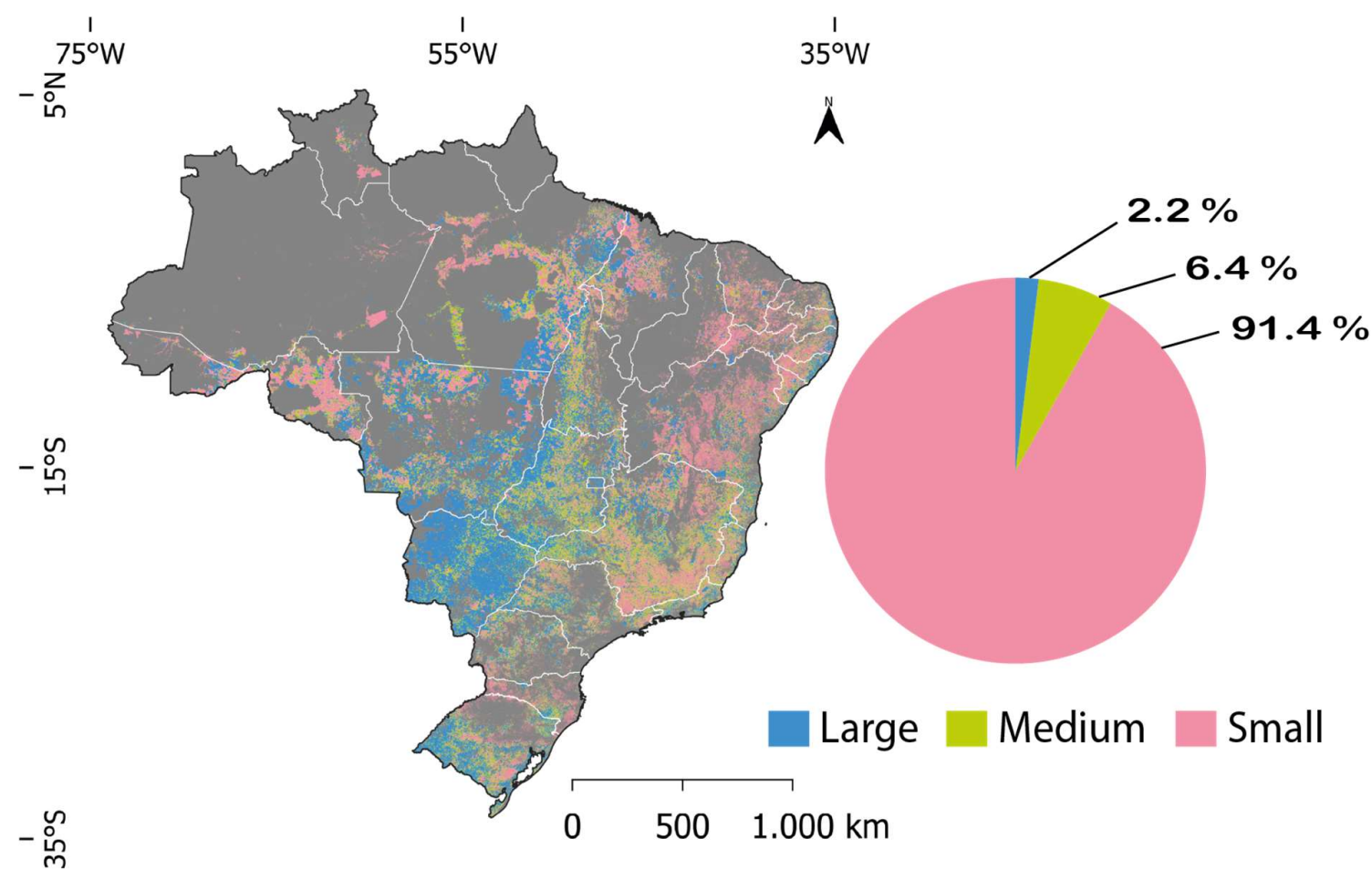

Figure 5. Spatial distribution of Brazilian rural properties by size class (Small, Medium and Large), according to the limits available in the CAR - Rural Environmental Registry.

Table 2. Distribution of the number of Brazilian rural properties regarding the dynamics of pasture quality in the period between 2010 and 2018.

\begin{tabular}{crrrr}
\hline \multirow{2}{*}{ Quality } & \multicolumn{4}{c}{ Number of rural properties } \\
\cline { 2 - 5 } & \multicolumn{1}{c}{ Small } & \multicolumn{1}{c}{ Medium } & \multicolumn{1}{c}{ Large } & \multicolumn{1}{c}{ Total } \\
\hline Stable & $1.451 .311(59,2 \%)$ & $97.200(57,3 \%)$ & $31.589(52,7 \%)$ & $1.580 .100(58,9 \%)$ \\
Increase & $595.445(24,3 \%)$ & $57.452(33,9 \%)$ & $24.696(41,2 \%)$ & $677.593(25,3 \%)$ \\
Reduction & $406.192(16,6 \%)$ & $15.027(8,9 \%)$ & $3.711(6,2 \%)$ & $424.930(15,8 \%)$ \\
\hline
\end{tabular}




\section{Total $\quad 2.452 .948(100 \%) \quad 169.679(100 \%) \quad 59.996(100 \%) \quad 2.682 .623(100 \%)$}
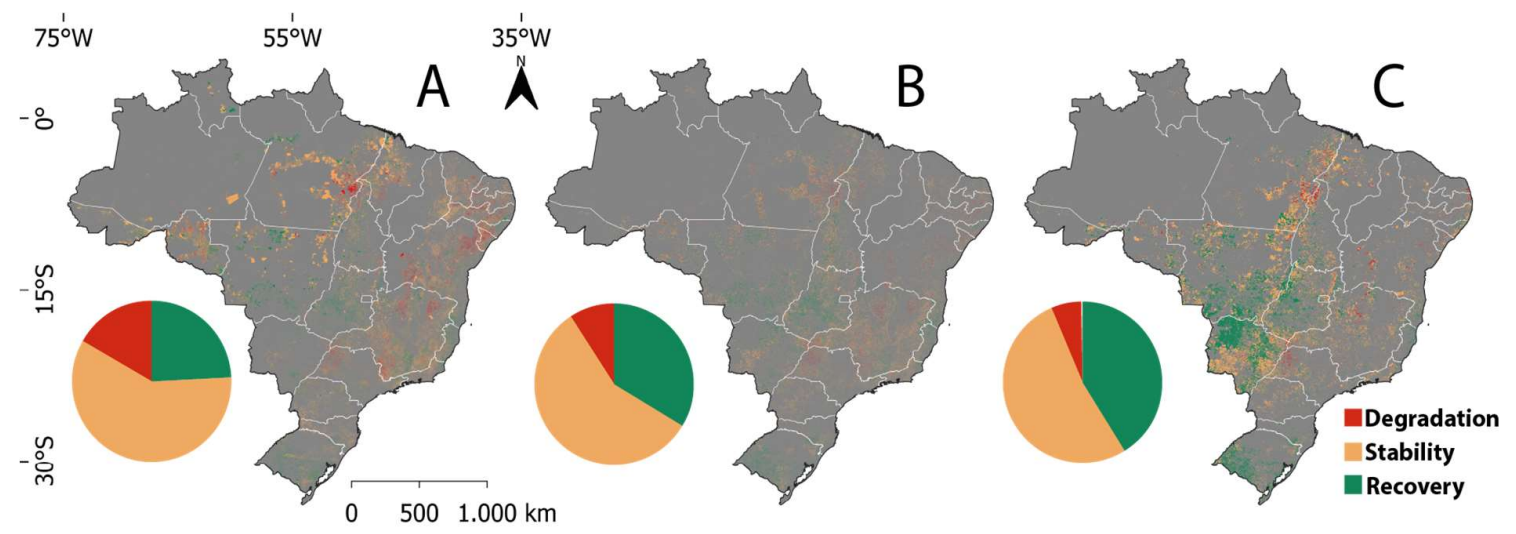

Figure 6. Spatial distribution of the dynamics in pasture quality in Brazilian rural properties between 2010 and 2018. ( $\mathrm{A}=$ Small properties, $\mathrm{B}=$ Medium properties, and $\mathrm{C}=$ Large properties)

An important question about the management of public resources applied to land use is related to its effectiveness, that is, whether properties that receive financial resources are able to increase their production. We observed that approximately $56 \%$ of the polygons with pastures that received funds from the $\mathrm{ABC}$ Plan showed no change in the quality of pastures, while in another $12 \%$ there was a reduction in quality (figure 7). Therefore, in approximately one third of the polygons (32\%) pastures were recovered in the period evaluated.

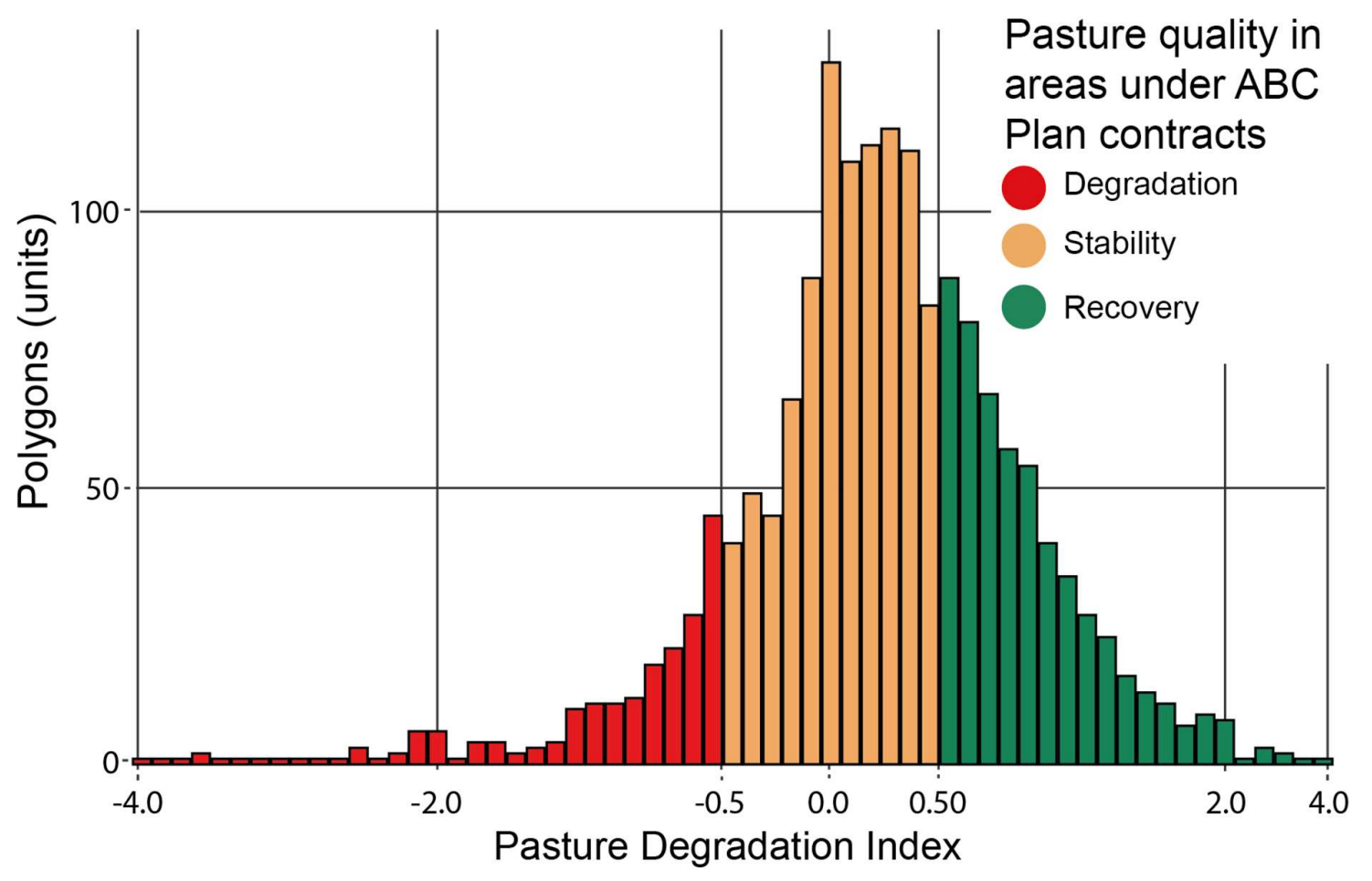


Figure 7. Distribution of polygons with $\mathrm{ABC}$ Plan financing contracts for the recovery of degraded pastures, in the period from 2016 to 2017, classified as loss (Degradation), gain (Recovery) or Stability in the quality of pastures.

\section{Discussion}

\subsection{Spatial and quality dynamics of pastures in Brazil}

The $\sim 0.9$ Mha reduction in the total area occupied by pasture between 2010 and 2018 is within the confidence interval of the mapping ( $\pm 2.5 \%$ ), reported by Parente et al. (2019); therefore, there was no significant variation in the area occupied by pastures in Brazil in this period of time. Studies suggest that the stabilization of the total area occupied by pastures in the country began in the late 2000s, after a period of great expansion in this land use class (Parente et al., 2019; Parente and Ferreira, 2018; Zalles et al., 2021). According to these authors, in less than three decades (i.e. between 1985 and 2010) there was an increase of $\sim 60$ Mha in the area occupied by pastures, equivalent to an increase rate of 2.4 Mha per year.

However, the temporal analysis of variations in the absolute values of area hides an intense spatial dynamic, as regions classified as pasture only in 2018 had a similar territorial extension to those that were no longer classified as such in that same year; i.e., there were gains and losses of pasture areas in equivalent amounts (around $31 \mathrm{Mha}$ ). As this is a considerable change in territorial terms, equivalent to the extension of countries like Germany or Italy, understanding the spatial dynamics of pastures in the country requires an assessment of the factors that are contributing to the retraction and expansion of this land use class. As they are two antagonistic processes, and due to the magnitude of variation in area, they can only coexist if they occur in different regions.

The retraction in pasture areas occurred mainly in the Center-West and Southeast regions of the country, while the expansion was detected predominantly in the North region. Several factors were identified as determinants of the spatial dynamics of pastures in Brazil, being intrinsically linked to the processes of land use and occupation prevalent in the country (Barona et al., 2010; Davidson et al., 2012; Sparovek et al., 2019). Although the processes are not completely clear, in Mato Grosso, the state responsible for about 25\% of the Brazilian beef exports (ABIEC, 2020), agricultural expansion in pasture areas between 2001 and 2004 accounted for more than $60 \%$ of new areas cultivated in the region, and forced a displacement of livestock activity to the North region (Morton et al., 2006). And on a broader scale, Parente 
and Ferreira (2018) identified a strong retraction in the pasture area and in the cattle herd in the Center-South region of the country, and an increase in both in the North region between 2000 and 2016. The pasture retraction areas were occupied by agriculture (i.e. soy, corn, cotton and sugarcane), predominantly in the Cerrado and Atlantic Forest biomes. On the other hand, the expansion took place in areas of conversion of native vegetation, mainly in the Amazon biome (Souza et al., 2020).

The expansion of agriculture over pasture areas is a common process in land use dynamics in Brazil, and has been recorded for decades (Barona et al., 2010; Cardille and Foley, 2003; Stabile et al., 2020), with economic factors being important drivers determining land use changes. Areas for conversion of native vegetation tend to be primarily occupied by pastures, as this class of land use generally has a lower implementation cost compared to other uses (Barona et al., 2010). Subsequently, areas with agricultural aptitude are converted to more profitable and generally more technified uses, such as grain production and sugarcane cultivation, consolidating the use of the area (Cardille and Foley, 2003; Souza et al., 2020). It is important to emphasize that economic factors are not always associated with the production system. Much of the deforestation in agricultural frontier regions has been attributed to real estate speculation and illegal union land grabbing (Stabile et al., 2020). In these regions, the removal of native vegetation usually occurs illegally (Azevedo et al., 2020) and the goal of the actors involved is land appreciation. Thus, deforested areas tend to be occupied with pastures, but without the objective of developing profitable livestock. The designation of vacant land areas, added to command and control policies, can be factors that discourage this practice, which is not environmentally sustainable (Stabile et al., 2020). This could contribute to a reduction in deforestation, and consequently an increase in the efficiency of livestock for the northern region, leading to changes in management, with gains in efficiency and productivity.

The current dynamics of land use and occupation have contributed to the maintenance of livestock production, as the increase in non-degraded pastures in 2018 has part of its composition coming from areas that were not previously classified as pastures. This process is due to the fact that pasture retraction occurs in predominantly degraded areas $(\mathrm{D} 1+\mathrm{D} 2)$, and newly converted areas are predominantly non-degraded (D0), since newly formed pastures tend to have high productivity in the first years of use, due to the high availability of nutrients, resulting from the process of conversion of native vegetation (Oliveira et al., 2004). However, this dynamic is not environmentally sustainable since expansion comes at the cost of deforestation (Parente et al., 2021; Souza et al., 2020). The good news is that changes in the 
livestock production system seem to be underway, since the aforementioned dynamic would explain the maintenance of production, but would not be enough to explain the support for the growth of the cattle herd, indicating an efficiency gain. In this context, the reduction in the proportion of pastures with some level of degradation (D1 + D2) between 2010 and 2018 (from $71 \%$ to $58 \%$ ), and the consequent increase in the non-degraded pasture area (D0), observed in the present study, shows an improvement in the quality of pastures and corroborates the increase in the efficiency of the livestock activity.

During this period there was an addition of $\sim 5.5$ million animals to the Brazilian cattle herd, equivalent to an annual increase rate of 0.7 million animals (IBGE, 2020). This increase was observed in a period in which there was no change in the total area occupied by pastures, indicating an improvement and increase in the support capacity in the livestock sector. Recent studies have identified this process of intensification of livestock activity, with gains in efficiency and productivity from the 2000s onwards (ABIEC, 2020; Dias et al., 2016; Parente et al., 2019). Analyzing data from the bovine herd and pasture areas (see LAPIG 2021), we identified that between 1985 and 2018, the bovine stocking increased from 0.8 to $0.92 \mathrm{AU} / \mathrm{ha}$ (Animal Unit per hectare). Without this average increase of $0.12 \mathrm{AU} / \mathrm{ha}$, an additional $15 \mathrm{Mha}$ would be necessary to the livestock system to support the cattle herd accounted for in 2018 (IBGE, 2020). However, on average, cattle stocking remains low and pastures are not very productive (Arantes et al., 2018). For decades, researchers have been warning about the need to promote changes in pasture management and rehabilitation of degraded areas for sustainable cattle raising (Dias Filho, 2011a; Mazzetto et al., 2015; Oliveira et al., 2004). The results observed in the present study indicate that these changes are possibly underway.

Spatially, the reduction in degraded areas was observed in the Midwest, Southeast and South regions, where areas of consolidated use, with a higher opportunity cost, predominate (Dias Filho, 2011b). This process is possibly driven by land appreciation, which can lead to investments to increase livestock productivity in areas that remain in this land use class. Increased profitability can lead to greater availability of resources for investments, resulting in a positive cycle of pasture improvement (Stabile et al., 2020). Better management and, consequently, a higher proportion of non-degraded pastures, does not always indicate a change in the owner's behavior or perception in relation to livestock, but rather a social dynamic in which owners who choose extensive livestock activities tend to migrate to frontier regions, where, with a lower land price, larger areas can be acquired, and continue to practice extensive cattle raising. The areas they occupied tend to be acquired by actors with greater capital and 
therefore with the necessary means to maintain intensive livestock farming, often bringing experiences and concepts from other sectors, resulting in professional administration for the livestock activity (Oliveira and Couto, 2018). Thus, it is expected that the proportion of areas with better quality pastures will increase in regions of consolidated use, as observed in this study.

Despite the aforementioned gain in efficiency, we observed an extensive area of pastures (44.3 Mha) classified as having severe degradation (D2) in 2018, that is, lowproductive pastures exceed in area the extension of countries such as Germany or Norway. Just over half of this area had already been classified as D2 in 2010, showing that low productivity is persisting over time. The cost of recovering the area increases in advanced stages of degradation, and this factor certainly contributed to the permanence of areas in this class, and a lower proportion of recovery compared to the recovery of pastures with intermediate degradation (Dias Filho, 2011a). The greatest dynamic in the intermediate degradation class is probably related to the traditional management of extensive livestock in Brazil, in which the pasture degradation process is common, due to the poorly technified management with absence of soil correction and fertilization process for maintenance of forage productivity (MarthaJúnior and Vilela, 2002; Volpe et al., 2008). In a first phase, there is an intermediate degradation (D1), which, in the absence of a management intervention to recover productivity, advances to severe degradation (D2) (Dias Filho, 2011a). Thus, intermediate degradation appears to be a transitory condition in the Brazilian livestock, which generally follows one of three paths: (a) the largest proportion is recovered, as observed in this study, and if there are no changes in management, it will possibly return to this class in a few years and it will be reformed again, in a vicious cycle; (b) a smaller proportion may progress to severe degradation due to the absence of intervention; and (c) part of the area leaves the livestock system, possibly through conversion to other uses or coverage.

\subsection{Relationship between the size of the rural property and the contribution of resources from the ABC Plan with the quality of pastures}

In numerical terms, most rural properties in Brazil are comprised of small areas, as also pointed out by (Sparovek et al., 2019). And pasture quality is strongly related to productivity, which in turn enables an increase in the economic return, due to improved management (technification + intensification). For this, the owner needs both technical assistance and financial resources (Garrett et al., 2018). However, the small producer usually has less equity, 
low access to credit lines from financial institutions, and they also lack technical assistance to intensify their productivity (Alencar et al., 2016; Castro and Pereira, 2017). Therefore, the greater proportion of quality loss observed in the present work in small farms illustrates this reality. At the other extreme, the higher proportion of gain in quality observed in large properties possibly reflects greater access to the financial resources needed to improve livestock activity, while at the same time evidencing an increase in socioeconomic inequality in the livestock sector.

The properties with gains in pasture quality are located mainly in the Midwest region of Brazil, where there were initiatives to recover degraded pastures such as the Novo Campo program, started in 2012, in the north of Mato Grosso (ICV, 2021). In 2009, after a period of high deforestation rates, more than 20 municipalities in Mato Grosso, which did not meet the deforestation reduction targets, were included in the Ministry of the Environment's (MMA) blacklist, which implied a reduction in revenues and restricted access to credits (Nepstad et al., 2014). In this context, initiatives such as the Novo Campo program have contributed to improving the quality of pastures in this region (Latawiec et al., 2017). Between 2016 and 2017, this was the region with the highest proportion of contracts for the recovery of degraded pastures under the RPD program, which may also have contributed to the results observed in this study.

The proportion of cases in which there was a gain in pasture quality in areas under contracts of the RPD program was higher than the quality gain observed for properties in general (32\% and $25 \%$, respectively), showing a positive effect of the program on the quality of pastures. On the other hand, more than half (56\%) of the polygons under contracts did not show quality gains, indicating that this positive effect is still low, since $100 \%$ of the contract areas are expected to have their pastures improved. It is noteworthy that the short period between signing the contract and the year evaluated in this study may not have been enough for changes in the quality class to be detected by the tool used, indicating that pastures are still in the initial stage of recovery in many of the polygons.

The results obtained in this work reinforce the assertions of several studies focused on the dynamics of land use and occupation in Brazil, which analyzed the role played by the country in food production and global food security and indicate that the current model of livestock production is unsustainable (Bustamante et al., 2012; Oliveira et al., 2004; Souza et al., 2020; Stabile et al., 2020; Strassburg et al., 2014). In the northern region of Brazil, the main 
agricultural frontier in the country and also in the world, there is still an intense process of converting vegetation into cultivated areas (agriculture or livestock). These anthropic actions affect the climate, biodiversity and ecosystem services in the country. Therefore, a new production model that prioritizes the intensification of livestock in already open areas can promote increased production and the release of land for grain production, sufficient to meet the demands of the coming decades, without the need to convert new areas of remnants of native vegetation (Lambin et al., 2013; Strassburg et al., 2014). The improvement in the quality of pastures observed in this study may indicate a step in this direction, but all the results indicate that there is still a long way to go towards a more sustainable and more productive cattle raising.

\section{Concluding remarks}

In this unprecedented study, we analyzed the dynamics of degradation of the Brazilian pastures in the last decade - 2010 to 2018 . During this period there was an increase in the quality and support capacity of pastures in the country. We observed that there were no changes in the total area occupied by pastures, while the percentage of non-degraded areas and the cattle herd increased, indicating that there were gains in productivity. The improvement in the quality of pastures, together with the increase observed in the cattle herd, indicate that the gain in productivity was due to intensification, i.e. a vertical increase in livestock production.

The increase in the area of non-degraded pastures occurred due to two factors: (a) retraction of pastures with intermediate or severe degradation in the center-south of the country, and conversion of areas of native vegetation to pastures in the northern region; (b) recovery of degraded pastures, which was 2.7 times larger than the area that lost quality in this period. Between 2010 and 2018, about 26.8 Mha were no longer classified as degraded, and in the same period, about 10.1 Mha were classified as degraded.

About $60 \%$ of rural properties with livestock activity showed no changes in the Pasture Degradation Index (IDP). On the other hand, the proportion of properties with gains in quality was higher than that of properties with a loss of quality, indicating that, on average, the degradation of pastures on rural properties is decreasing. However, this change is not homogeneous across size classes. The proportion of small properties that gained quality is about twice as small as that of large properties, while the proportion with loss of quality was about three times greater. The increase in inequality between these classes may be associated with greater availability of financial and technological resources used in the livestock activity in large properties. One third of the areas with ABC Plan contracts showed quality gains, however 
the results were not sufficient to draw conclusions about the Plan's effectiveness, requiring long-term studies.

\section{Acknowledgments}

This work, part of the MapBiomas initiative (http://mapbiomas.org), was supported by the Gordon and Betty Moore Foundation (GBMF), The Nature Conservancy (TNC), the Goiás State Research Foundation (FAPEG), the Coordination for the Improvement of Higher Education Personnel (CAPES), and the Brazilian Research Council (CNPq).

\section{Author Contributions}

C.S., L.F. and L.P. conceived the idea and the methodological approach of the study. C.S. and V.M. processed the data and, together with L.F. analyzed the results. All the authors contributed to the discussions and writing or revision of the manuscript. L.F. was responsible for the funding acquisition.

\section{Conflicts of Interest}

The authors declare no conflict of interest.

\section{References}

ABIEC, 2020. Perfil da pecuária no Brasil 2020, BeefREPORT.

Aguiar, D.A., Mello, M.P., Nogueira, S.F., Gonçalves, F.G., Adami, M., Rudorff, B.F.T., 2017. MODIS Time Series to Detect Anthropogenic Interventions and Degradation Processes in Tropical Pasture. Remote Sens. 9, 73. https://doi.org/10.3390/rs9010073

Alencar, A., Pereira, C., Castro, I., Cardoso, A., Souza, L., Costa, R., Bentes, A.J., Stella, O., Azevedo, A., Gomes, J., Novaes, R., 2016. Desmatamento nos Assentamentos da Amazônia: histórico, tendências e oportunidades. IPAM - Inst. Pesqui. Ambient. da Amaz. 93.

Alves-Pinto, H.N., Newton, P., Guedes Pinto, L.F., 2015. Reducing deforestation and enhancing sustainability in commodity supply chains: Interactions between governance interventions and cattle certification in Brazil. Trop. Conserv. Sci. 8, 1053-1079. https://doi.org/10.1177/194008291500800414

Andrade, R.G., Aparecida, C., Rodrigues, G., Del, I., Sanches, A., Enrique, F., Quartaroli, C.F., 2013. Uso de técnicas de sensoriamento remoto na detecção de processos de degradação de pastagens. Eng. na Agric. 21, 234-243.

Arantes, A.E., Couto, V.R. de M., Sano, E.E., Ferreira, L.G., 2018. Livestock intensification potential in Brazil based on agricultural census and satellite data analysis. Pesqui. Agropecuária Bras. 53, 1053-1060. https://doi.org/10.1590/s0100-204x2018000900009

Arantes, A.E., Ferreira, L.G., Coe, M.T., 2016. The seasonal carbon and water balances of the Cerrado environment of Brazil: Past, present, and future influences of land cover and land use. ISPRS J. Photogramm. Remote Sens. 117, 66-78. 
https://doi.org/10.1016/j.isprsjprs.2016.02.008

Azevedo, T.R. de, Rosa, M.R., Shimbo, J.Z., Martin, E.V., Oliveira, M.G. de, 2020. Relatório Anual do Desmatamento no Brasil. Mapbiomas 49.

Barona, E., Ramankutty, N., Hyman, G., Coomes, O.T., 2010. The role of pasture and soybean in deforestation of the Brazilian Amazon. Environ. Res. Lett. 5. https://doi.org/10.1088/1748-9326/5/2/024002

Braz, S.P., Urquiaga, S., Alves, B.J.R., Jantalia, C.P., Guimarães, A.P., dos Santos, C.A., dos Santos, S.C., Machado Pinheiro, É.F., Boddey, R.M., 2013. Soil Carbon Stocks under Productive and Brachiaria Degraded Pastures in the Brazilian Cerrado. Soil Sci. Soc. Am. J. 77, 914-928. https://doi.org/10.2136/sssaj2012.0269

Brito, J.L.S., Arantes, A.E., Ferreira, L.G., Sano, E.E., 2018. MODIS estimates of pasture productivity in the Cerrado based on ground and Landsat-8 data extrapolations. J. Appl. Remote Sens. 12, 1. https://doi.org/10.1117/1.JRS.12.026006

Bustamante, M.M.C., Nobre, C.A., Smeraldi, R., Aguiar, A.P.D., Barioni, L.G., Ferreira, L.G., Longo, K., May, P., Pinto, A.S., Ometto, J.P.H.B., 2012. Estimating greenhouse gas emissions from cattle raising in Brazil. Clim. Change 115, 559-577. https://doi.org/10.1007/s10584-012-0443-3

Cardille, J.A., Foley, J.A., 2003. Agricultural land-use change in Brazilian Amazônia between 1980 and 1995: Evidence from integrated satellite and census data. Remote Sens. Environ. 87, 551-562. https://doi.org/10.1016/j.rse.2002.09.001

Castro, C.N., Pereira, C.N., 2017. Agricultura familiar, assistência técnica e extensão rural e a política nacional de Ater. Texto para discussão / Inst. Pesqui. Econômica Apl. 1, 48.

Chen, Y., Guerschman, J., Shendryk, Y., Henry, D., Harrison, M.T., 2021. Estimating Pasture Biomass Using Sentinel-2 Imagery and Machine Learning. Remote Sens. 13, 603. https://doi.org/10.3390/rs13040603

Davidson, E.A., de Araújo, A.C., Artaxo, P., Balch, J.K., Brown, I.F., C. Bustamante, M.M., Coe, M.T., DeFries, R.S., Keller, M., Longo, M., Munger, J.W., Schroeder, W., SoaresFilho, B.S., Souza, C.M., Wofsy, S.C., 2012. The Amazon basin in transition. Nature 481, 321-328. https://doi.org/10.1038/nature10717

Dias Filho, M.B., 2014. Diagnóstico das Pastagens no Brasil. Embrapa Amaz. Orient. 36.

Dias Filho, M.B., 2011a. Degradação de Pastagens: Processos, Causas e Estratégias de Recuperação. 4th ed. Belém. 204.

Dias Filho, M.B., 2011b. Os desafios da produção animal em pastagens na fronteira agrícola brasileira. Rev. Bras. Zootec. 40, 243-252.

Dias, L.C.P., Pimenta, F.M., Santos, A.B., Costa, M.H., Ladle, R.J., 2016. Patterns of land use, extensification, and intensification of Brazilian agriculture. Glob. Chang. Biol. 22, $2887-$ 2903. https://doi.org/10.1111/gcb.13314

Dos Reis, A.A., Werner, J.P.S., Silva, B.C., Figueiredo, G.K.D.A., Antunes, J.F.G., Esquerdo, 
J.C.D.M., Coutinho, A.C., Lamparelli, R.A.C., Rocha, J. V., Magalhães, P.S.G., 2020. Monitoring Pasture Aboveground Biomass and Canopy Height in an Integrated CropLivestock System Using Textural Information from PlanetScope Imagery. Remote Sens. 12, 2534. https://doi.org/10.3390/rs 12162534

Eckert, S., Hüsler, F., Liniger, H., Hodel, E., 2015. Trend analysis of MODIS NDVI time series for detecting land degradation and regeneration in Mongolia. J. Arid Environ. 113, 16-28. https://doi.org/10.1016/j.jaridenv.2014.09.001

EMBRAPA, 2021. Projeto GeoDegrade [WWW Document]. URL http://www.geodegrade.cnpm.embrapa.br/apresentacao (accessed 1.10.21).

FAO, 2019. Five practical actions towards low-carbon livestock.

Gao, Q., Li, Y., Wan, Y., Lin, E., Xiong, W., Jiangcun, W., Wang, B., Li, W., 2006. Grassland degradation in Northern Tibet based on remote sensing data. J. Geogr. Sci. 16, 165-173. https://doi.org/10.1007/s11442-006-0204-1

Gargiulo, J., Clark, C., Lyons, N., de Veyrac, G., Beale, P., Garcia, S., 2020. Spatial and temporal pasture biomass estimation integrating electronic plate meter, planet cubesats and sentinel-2 satellite data. Remote Sens. 12, 1-16. https://doi.org/10.3390/rs12193222

Garrett, R.D., Koh, I., Lambin, E.F., le Polain de Waroux, Y., Kastens, J.H., Brown, J.C., 2018. Intensification in agriculture-forest frontiers: Land use responses to development and conservation policies in Brazil. Glob. Environ. Chang. 53, 233-243. https://doi.org/10.1016/j.gloenvcha.2018.09.011

Gosch, M.S., Parente, L.L., Ferreira, N.C., Oliveira, A.R. de O., FERREIRA, L.G., 2020. Pastagens degradadas, uma herança dos imóveis rurais desapropriados para os assentamentos rurais do Cerrado goiano. Rev. Campo-Território 15, 202-229. https://doi.org/10.14393/rct153508

IBGE, 2020. Pesquisa Pecuária Municipal [WWW Document]. URL https://sidra.ibge.gov.br/pesquisa/ppm/quadros/brasil/2019 (accessed 12.19.20).

ICV, 2021. Programa Novo Campo [WWW Document]. URL https://www.icv.org.br/projeto_especial/programa-novo-campo/(accessed 1.10.21).

Lahsen, M., Bustamante, M.M.C., Dalla-Nora, E.L., 2016. Undervaluing and Overexploiting the Brazilian Cerrado at Our Peril. Environ. Sci. Policy Sustain. Dev. 58, 4-15. https://doi.org/10.1080/00139157.2016.1229537

Lambin, E.F., Gibbs, H.K., Ferreira, L., Grau, R., Mayaux, P., Meyfroidt, P., Morton, D.C., Rudel, T.K., Gasparri, I., Munger, J., 2013. Estimating the world's potentially available cropland using a bottom-up approach. Glob. Environ. Chang. 23, 892-901. https://doi.org/10.1016/j.gloenvcha.2013.05.005

LAPIG, 2020. Atlas Digital das Pastagens Brasileiras [WWW Document]. URL https://pastagem.org/atlas (accessed 12.19.20).

Latawiec, A.E., Strassburg, B.B.N., Silva, D., Alves-Pinto, H.N., Feltran-Barbieri, R., Castro, A., Iribarrem, A., Rangel, M.C., Kalif, K.A.B., Gardner, T., Beduschi, F., 2017. Improving 
land management in Brazil: A perspective from producers. Agric. Ecosyst. Environ. 240, 276-286. https://doi.org/10.1016/j.agee.2017.01.043

Latawiec, A.E., Strassburg, B.B.N., Valentim, J.F., Ramos, F., Alves-Pinto, H.N., 2014. Intensification of cattle ranching production systems: Socioeconomic and environmental synergies and risks in Brazil. Animal 8, 1255-1263. https://doi.org/10.1017/S1751731114001566

MAPA, 2012. Plano Setorial de Mitigação e Adaptação às Mudanças Climáticas para Consolidação da Economia de Baixa Emissão de Carbono na Agricultura - PLANO ABC, Revista Brasileira de Geografia Física.

Martha-Júnior, G.B., Vilela, L., 2002. Pastagens no Cerrado: Baixa Produtividade pelo Pastagens no Cerrado : Embrapa 30.

Mazzetto, A.M., Feigl, B.J., Schils, R.L.M., Cerri, C.C.E.P., Cerri, C.C.E.P., 2015. Improved pasture and herd management to reduce greenhouse gas emissions from a Brazilian beef production system. Livest. Sci. 175, 101-112. https://doi.org/10.1016/j.livsci.2015.02.014

Morton, D.C., DeFries, R.S., Shimabukuro, Y.E., Anderson, L.O., Arai, E., Del Bon EspiritoSanto, F., Freitas, R., Morisette, J., 2006. Cropland expansion changes deforestation dynamics in the southern Brazilian Amazon. Proc. Natl. Acad. Sci. U. S. A. 103, $14637-$ 14641. https://doi.org/10.1073/pnas.0606377103

Nepstad, D., McGrath, D., Stickler, C., Alencar, A., Azevedo, A., Swette, B., Bezerra, T., DiGiano, M., Shimada, J., Seroa da Motta, R., Armijo, E., Castello, L., Brando, P., Hansen, M.C., McGrath-Horn, M., Carvalho, O., Hess, L., 2014. Slowing Amazon deforestation through public policy and interventions in beef and soy supply chains. Science (80-. ). 344, 1118-1123. https://doi.org/10.1126/science. 1248525

Olexa, E.M., Lawrence, R.L., 2014. Performance and effects of land cover type on synthetic surface reflectance data and NDVI estimates for assessment and monitoring of semi-arid rangeland. Int. J. Appl. Earth Obs. Geoinf. 30, 30-41. https://doi.org/10.1016/j.jag.2014.01.008

Oliveira, E.R. de, Couto, V.R.M., 2018. Productive and Economic Viability of Raising Beef Cattle in the Savanna of the Brazilian State of Goiás. Rev. Econ. e Sociol. Rural 56, 395410. https://doi.org/10.1590/1234-56781806-94790560302

Oliveira, O.C., Oliveira, I.P., Alves, B.J.R., Urquiaga, S., Boddey, R.M., 2004. Chemical and biological indicators of decline/degradation of Brachiaria pastures in the Brazilian Cerrado. Agric. Ecosyst. Environ. 103, 289-300. https://doi.org/10.1016/j.agee.2003.12.004

Olofsson, P., Foody, G.M., Herold, M., Stehman, S. V., Woodcock, C.E., Wulder, M.A., 2014. Good practices for estimating area and assessing accuracy of land change. Remote Sens. Environ. 148, 42-57. https://doi.org/10.1016/j.rse.2014.02.015

Parente, L., Ferreira, L., 2018. Assessing the spatial and occupation dynamics of the Brazilian pasturelands based on the automated classification of MODIS images from 2000 to 2016. Remote Sens. 10, 606. https://doi.org/10.3390/rs10040606 
Parente, L., Mesquita, V., Miziara, F., Baumann, L., Ferreira, L., 2019. Assessing the pasturelands and livestock dynamics in Brazil, from 1985 to 2017: A novel approach based on high spatial resolution imagery and Google Earth Engine cloud computing. Remote Sens. Environ. 232, 111301. https://doi.org/10.1016/j.rse.2019.111301

Parente, L., Nogueira, S., Baumann, L., Almeida, C., Maurano, L., Affonso, A.G., Ferreira, L., 2021. Quality assessment of the PRODES Cerrado deforestation data. Remote Sens. Appl. Soc. Environ. 21. https://doi.org/10.1016/j.rsase.2020.100444

Pereira, L.F., Ferreira, C.F.C., Guimarães, R.M.F., 2018. Manejo, Qualidade E Dinâmica Da Degradação De Pastagens Na Mata Atlântica De Minas Gerais - Brasil. Nativa 6, 370. https://doi.org/10.31413/nativa.v6i4.5542

Pereira, O.J.R., Ferreira, L.G., Pinto, F., Baumgarten, L., 2018. Assessing pasture degradation in the Brazilian Cerrado based on the analysis of MODIS NDVI time-series. Remote Sens. 10. https://doi.org/10.3390/rs10111761

Reinermann, S., Asam, S., Kuenzer, C., 2020. Remote sensing of grassland production and management-A review. Remote Sens. 12. https://doi.org/10.3390/rs12121949

Rouse, W., Haas, R.H., Deering, D.W., 1973. Monitoring vegetation systems in the Great Plains with ERTS, NASA SP-351. Third ERTS-1 Symp. Vol. 1.

Souza, C.M., Shimbo, J.Z., Rosa, M.R., Parente, L.L., Alencar, A.A., Rudorff, B.F.T., Hasenack, H., Matsumoto, M., Ferreira, L.G., Souza-Filho, P.W.M., de Oliveira, S.W., Rocha, W.F., Fonseca, A. V., Marques, C.B., Diniz, C.G., Costa, D., Monteiro, D., Rosa, E.R., Vélez-Martin, E., Weber, E.J., Lenti, F.E.B., Paternost, F.F., Pareyn, F.G.C., Siqueira, J. V., Viera, J.L., Neto, L.C.F., Saraiva, M.M., Sales, M.H., Salgado, M.P.G., Vasconcelos, R., Galano, S., Mesquita, V. V., Azevedo, T., 2020. Reconstructing three decades of land use and land cover changes in brazilian biomes with landsat archive and earth engine. Remote Sens. 12. https://doi.org/10.3390/RS12172735

Sparovek, G., Reydon, B.P., Guedes Pinto, L.F., Faria, V., de Freitas, F.L.M., Azevedo-Ramos, C., Gardner, T., Hamamura, C., Rajão, R., Cerignoni, F., Siqueira, G.P., Carvalho, T., Alencar, A., Ribeiro, V., 2019. Who owns Brazilian lands? Land use policy 87, 104062. https://doi.org/10.1016/j.landusepol.2019.104062

Stabile, M.C.C., Guimarães, A.L., Silva, D.S., Ribeiro, V., Macedo, M.N., Coe, M.T., Pinto, E., Moutinho, P., Alencar, A., 2020. Solving Brazil's land use puzzle: Increasing production and slowing Amazon deforestation. Land use policy 91, 104362. https://doi.org/10.1016/j.landusepol.2019.104362

Strassburg, B.B.N., Latawiec, A.E., Barioni, L.G., Nobre, C.A., da Silva, V.P., Valentim, J.F., Vianna, M., Assad, E.D., 2014. When enough should be enough: Improving the use of current agricultural lands could meet production demands and spare natural habitats in Brazil. Glob. Environ. Chang. 28, 84-97. https://doi.org/10.1016/j.gloenvcha.2014.06.001

USDA, 2020. Livestock and Products Annual, Brazil 2020.

Vieira-Filho, J.E.R., Fishlow, A., 2017. Agricultura e Indústria no Brasil: inovação e competitividade, Ipea. 
Volpe, E., Marchetti, M.E., Macedo, M.C.M., Rosa, E.J., 2008. Renovação de pastagem degradada com calagem, adubação e leguminosa consorciada em neossolo Quartzarênico. Acta Sci. - Agron. 30, 131-138. https://doi.org/10.4025/actasciagron.v30i1.1162

West, P.C., Gerber, J.S., Engstrom, P.M., Mueller, N.D., Brauman, K.A., Carlson, K.M., Cassidy, E.S., Johnston, M., MacDonald, G.K., Ray, D.K., Siebert, S., 2014. Leverage points for improving global food security and the environment. Science (80-. ). 345, 325328. https://doi.org/10.1126/science. 1246067

Zalles, V., Hansen, M.C., Potapov, P. V, Parker, D., Stehman, S. V, Pickens, A.H., Parente, L.L., Ferreira, L.G., Song, X., Hernandez-Serna, A., Kommareddy, I., 2021. Rapid expansion of human impact on natural land in South America since 1985. Sci. Adv. 7, eabg1620. https://doi.org/10.1126/sciadv.abg1620 